The text is well-referenced, and suggestions for further reading are given at the end of each chapter.

In conclusion, this book would be a welcome addition to medical and nursing libraries, and, although aimed specifically at nurses, medical staff who maintain a holistic approach to care should also find this book both interesting and informative.

JANE WARNER formerly Nurse Teacher, Queen Elizabeth II Hospital, Welwyn Garden City, Hertfordshire.

\section{Ethics in Nursing: the Caring Relationship}

Verena Tschudin, 151 pages, London, £7.95, Heinemann Nursing, 1986.

This book was published at a time when the nursing process (a system of individualised care comprising assessment, planning, implementation and evaluation of care) had been established throughout most hospitals and in the community. The concept of nurses being in partnership with their patients, together with the increasing utilisation of medical technology, has therefore led nurses to focus upon ethical aspects of their work.

By writing this book, the author assists the nurse to gain insight into matters pertaining to nursing ethics. The first chapter sets the scene in terms of the role of the nurse today. In the second chapter, the author delves into the specific nature of the caring relationship as it affects nursing. Her arguments are well supported with valuable references.

Chapter three is devoted to the exposition of ethical theories. The author contrasts morality with ethics, and proceeds by describing the normative (prescriptive) and descriptive approaches to ethics as allied to health care. The ethical theories of consequentialism and nonconsequentialism are explored together with their implications for decisionmaking in nursing. The case of prescribing oral contraceptives without parental consent for girls under the age of 16 is highlighted. The author completes the chapter by discussing the five principles of ethics which are applicable in many nursing situations.

The book continues by raising the topics of values, attitudes and beliefs. The author emphasises that not only should nurses be aware of their own values, they should also understand and respect their patients' values in order for effective care to be undertaken. An overview of some professional Codes is included in the book, but it is noted that these Codes are limited in their scope to protect nurses in specific stated situations.

Detailed discussion of certain areas of ethics are put forward in the following chapters of this book, including nurses' rights and responsibilities, patient advocacy, accountability and loyalty to peers and patients. Conflicts that may arise pertaining to these areas are expanded upon.

Ethical decision-making, and the steps that the nurse must take in order for this process to happen are described in depth in the final chapters of this book. The nature of ethical dilemmas is put forward.

Overall, this book should serve to raise nurses' consciousness of the ethical issues that are constantly being met within a framework of the giving of individualised care. Nurses, especially those at the 'sharp end', ie, the bedside, will be able strongly to identify with these ethical issues.

Ethics in Nursing may be strongly recommended, certainly for nurses, and also for those interested in all aspects of medical and nursing ethics.

JANE WARNER formerly Nurse Teacher, Queen Elizabeth II Hospital, Welwyn Garden City, Hertfordshire.

\section{Human Embryos: The Debate on Assisted Reproduction}

C R Austin, 183 + vii pages, Oxford, £6.95, Oxford University

Press, 1989.

Inasmuch as any meaningful discussion of medical ethics must be grounded in the science and practice of the matter discussed, the first merit of $C \mathbf{R}$ Austin's book is that it provides that knowledge. (His competence in the field is amply evidenced by, inter alia, the eight volumes on Reproduction in Mammals which he edited with R V Short for Cambridge University Press). His first chapter gives a concise and illustrated description of the transmission of life from the formation of the gametes, egg and sperm, through fertilisation and cleavage to embryogenesis and fetal growth, with indications of the hazards encountered on the way. His second chapter outlines the scope of variations, encouragements and diversions made possible by human intervention, with timely corrections of popular misunderstandings of 'genetic engineering', gene therapy, cloning, hybrids, chimaeras and the like. Two chapters follow on the reasons for infertility and on ways of overcoming it. A fifth chapter, on ethics and law, examines some of the ethical and pseudo-ethical objections brought against infertility treatment and preembryo research, and reflects on what the law might reasonably be expected to contribute to the assurance of good practice.

The facts are not presented without comment and interpretation, and the book is the better for it. Other commentators' theories on 'when life begins' (a biological question too often dressed up as an ethical question) are fairly stated; and this makes Austin's own speculation the more interesting. His words are so compact, and exactitude so necessary, that they should be quoted:

'Almost the whole of the embry manifestly develops into the placentr etc, and no one can deny that, with onl a small fraction becoming (eventually the fetus. So the sequence can be stated rationally as follows: a very small part of the ovary (an oocyte, in fact) become an embryo, and a very small part of the embryo (the disc or plate) becomes the fetus. The inference is clear: the embryo should be regarded as an organ like the ovary, and as such is not entitled to the respect due to something destined to become a person. The embryonic and fetal parts are easily distinguished, a notable fact being that the fetal component grows much faster than the embryo-placental component' (p18).

After rehearsing the scientific and logical difficulty in insisting on the term 'embryo' for the early conceptus during cleavage, Austin adds:

'By an alternative system, an embryo originates as a very small part of a preembryo, and co-exists with the preembryo as the latter differentiates into placenta, etc, prior to becoming a fetus (p20).

On this basis of biological fact the chapter on ethics can discuss the attribution of 'personhood' and of human rights to the pre-implantation embryo. The understandable wish to do so can rest only on an imagined and 
unreal picture of a tiny baby claiming protection - which the pre-embryo is not; and the only authoritative support for such a view comes from the Church (he means the Roman Catholic Church), in which the position is demonstrably a novelty. At this point St Thomas Aquinas and the animation tradition is properly invoked. Unfortunately on p30 Austin appears to have followed Glanville Williams in his interpretation of St Thomas's language, to assert that he took quickening as the first indication of life. Animatus in Aquinas, as in the writing of philosophers, moralists and canonists for centuries, refers specifically to 'animation' in the Aristotelian sense the point when the morphology of the organism revealed or displayed that its animating or organising principle was a 'rational soul', that of a man and not of an animal. Inevitably animatus came in time to be identified with the subjective experience of quickening (vivificatus) and as such the concept passed into the English common law. This minor blemish detracts little from a very good and useful book.

G R DUNSTAN Department of Theology, The University of Exeter.

\section{Christian Ethics in Health Care}

John Wilkinson, 510 pages, Edinburgh, \{27.50, The Handsel Press, 1988.

This is a very ambitious book intended to guide Christian health workers in the ethical problems they face. By articulating ethical principles for thought and action, Wilkinson hopes to have produced a book of more lasting value than one which proceeded from problems or issues.

The book is in three parts: Christian ethics in outline, Health care ethics in history, and Christian ethics in health care. Given the strong emphasis on a principled approach it is not clear why so many issues get discussed in part three, yet it is just as well because this is the best part of the book. There are chapters on the beginning of life, the close of life, human experimentation and consent, resource allocation, health care relationships, and AIDS. It is not always clear that the Christian contribution to these discussions is as singular or normative as the author might have liked.

Wilkinson stands in a tradition in which theology and ethics cannot be separated. He writes of there being a Christian world view and a Christian ethical system "based on the character of God as revealed in Jesus Christ his Son and on his creation of the world and of man' ( $\mathrm{p} x)$. However, the discussion of particular issues frequently admits a degree of pluralism in Christianity. Whilst a helpful and clear methodology is given in the first section of the book too much of the discussion is frustrating. No one could deal justly with natural morality in six pages or biblical ethics in twelve pages. It would have been useful to have indicated more clearly the authority of the Bible. Its absolute authority seems to become relative as the particular is discussed and the various sources of Christian ethics come into conflict.

A more positive appreciation of the descriptive and analytical strands of ethics might have helped the third section of the book. In one part of the discussion of the beginning of life the phrase 'the termination of pregnancy' is abandoned in favour of 'abortion' and 'the unborn contents of the mother's uterus' in favour of 'child'. The justification is brevity, with no recognition of the value-loaded nature of the descriptions.

Despite these major reservations this book is a fine example of someone wrestling faithfully with ethical dilemmas. There is much to be gained here by Christians involved in health care, though the approach is more limited than the author himself is prepared to admit.

NICHOLAS HOLTAM, Christ Church, Isle of Dogs, London E14.

\section{Ethics in Nursing Practice: Basic Principles and Their Application}

F J Fitzpatrick, 290 pages, London, £9.95, The Linacre Centre, 1988.

This book should carry a more obvious 'government health warning' than it does. That is to say its title does not reveal the fact that it is a book which has more to do with Catholic moral principles and standpoints than with a more general notion of nursing ethics. The fact that the book comes out of the Linacre Centre gives a clue to its purpose and the foreword makes it very clear what this book is about. It states: 'The Governors and staff of the centre were made aware at an early stage in our existence of the need for a comprehensive account of nursing ethics which would be both faithful to Catholic moral tradition and accessible to a wider audience'.

The book stands on its own terms, that is as a guide to Catholic nurses in clinical practice. I am not so sure of its appeal to a 'wider audience'. The chapter dealing with Issues in sexual ethics is perhaps the most obvious example of the book's specific outlook. There are four practices which Fitzpatrick points out are 'objectionable' from the Catholic viewpoint. These are contraception, sterilisation, artificial insemination and in vitro fertilisation. In this chapter the Catholic beliefs are well articulated but little time is given to the idea that those who do not hold these views might have their rights compromised if they are nursed by someone who is primarily concerned with keeping faith and conscience intact.

The position taken leads to some rather bizarre lines of argument. For instance, in an attempt to maintain the inseparable link between the unitive and procreative meanings of human sexual activity Fitzpatrick argues thus: 'If ... sexual intercourse is intrinsically bound up with procreation, and if, also, the begetting and raising of children is appropriate only in the context of a single man-woman couple who undertake an unshakable commitment to care for their children, we can see why extra-marital affairs, homosexual practices and pederasty are to be condemned'.

I have focussed on what I see to be the less useful, in a general sense, aspects of this work and it would be unfair to leave the review at that. The work opens with a few general remarks about caring, the role of the nurse in terms of dependence and independence viz a viz medicine, the primacy of caring in nursing and the importance of health. There is a discussion of codes of ethics and discipline in nursing.

There is a useful introductory account of 'morality and objective truth'. After an enlightening discussion of emotivism and subjective-report theory, Fitzpatrick rather undercuts his, up until then even-handed approach, by asserting that 'although the idea that moral beliefs are not objectively true or false is clearly fashionable at present, nobody who ever makes moral claims - and surely that means all of us - can take it seriously. Clearly there is such a thing as moral truth...'. 